Article

\title{
An In Silico Study of the Antioxidant Ability for Two Caffeine Analogs Using Molecular Docking and Quantum Chemical Methods
}

\author{
Josivan da Silva Costa ${ }^{1,2,3}{ }^{(0}$, Ryan da Silva Ramos ${ }^{2,3} \mathbb{1}^{-}$, Karina da Silva Lopes Costa ${ }^{2}$, \\ Davi do Socorro Barros Brasil ${ }^{4}$, Carlos Henrique Tomich de Paula da Silva ${ }^{5}$, \\ Elenilze Figueiredo Batista Ferreira ${ }^{2}$, Rosivaldo dos Santos Borges ${ }^{1}$, Joaquín María Campos ${ }^{6}{ }^{\infty}$, \\ Williams Jorge da Cruz Macêdo ${ }^{1,3}$ and Cleydson Breno Rodrigues dos Santos ${ }^{2,3,6, *(D)}$ \\ 1 Postgraduate Program in Biotechnology and Biodiversity-Network BIONORTE, Federal University of Pará, \\ Rua Augusto Corrêa, 01, Belém, Pará 66075110, Brazil; josivan.chemistry@gmail.com (J.d.S.C.); \\ lqfmed@gmail.com (R.d.S.B.); williams.macedo@ufra.edu.br (W.J.d.C.M.) \\ 2 Laboratory of Modeling and Computational Chemistry, Department of Biological Sciences, \\ Federal University of Amapá, Rod. Juscelino Kubitschek, Km 02, s/n, Macapá, Amapá 68902-280, Brazil; \\ ryanquimico@hotmail.com (R.d.S.R.); karinalopesfarm@gmail.com (K.d.S.L.C.); \\ elenilze@yahoo.com.br (E.F.B.F.) \\ 3 Laboratory of Molecular Modeling and Simulation System, Federal Rural University of Amazônia, \\ Rua João Pessoa, 121, Capanema, Pará 68700-030, Brazil \\ 4 Institute of Technology, Federal University of Pará, Av. Augusto Corrêa, 01, Belém, Pará 66075-900, Brazil; \\ davibb@ufpa.br \\ 5 Computational Laboratory of Pharmaceutical Chemistry, Faculty of Pharmaceutical Sciences of Ribeirão \\ Preto, São Paulo 14040-903, Brazil; tomich@fcfrp.usp.br \\ 6 Department of Pharmaceutical and Organic Chemistry, University of Granada, Campus of Cartuja, \\ 18071 Granada, Spain; jmcampos@ugr.es \\ * Correspondence: breno@unifap.br; Tel.: +55-96-4009-2699
}

Received: 12 August 2018; Accepted: 11 October 2018; Published: 29 October 2018

\begin{abstract}
The antioxidant activity of molecules constitutes an important factor for the regulation of redox homeostasis and reduction of the oxidative stress. Cells affected by oxidative stress can undergo genetic alteration, causing structural changes and promoting the onset of chronic diseases, such as cancer. We have performed an in silico study to evaluate the antioxidant potential of two molecules of the zinc database: ZINC08706191 (Z91) and ZINC08992920 (Z20). Molecular docking, quantum chemical calculations (HF/6-31G**) and Pearson's correlation have been performed. Molecular docking results of Z91 and Z20 showed both the lower binding affinity (BA) and inhibition constant $(\mathrm{Ki})$ values for the receptor-ligand interactions in the three tested enzymes (cytochrome P450- CP450, myeloperoxidase-MP and NADPH oxidase- NO) than the control molecules (5-fluorouracil—FLU, melatonin-MEL and dextromethorphan-DEX, for each receptor respectively). Molecular descriptors were correlated with $\mathrm{Ki}$ and strong correlations were observed for the CP450, MP and NO receptors. These and other results attest the significant antioxidant ability of Z91 and Z20, that may be indicated for further analyses in relation to the control of oxidative stress and as possible antioxidant agents to be used in the pharmaceutical industry.
\end{abstract}

Keywords: antioxidant potential; molecular descriptors; molecular docking; binding free energy; free radicals; oxidative stress 


\section{Introduction}

Oxidants play a key role in maintaining the redox homeostasis of cells. However, in large quantities an imbalance can be triggered. Reactive Oxygen Species (ROS) resulting from aerobic respiration are examples of extremely unstable oxidants that can collide with other species (molecules or biomacromolecules), causing their transformation (oxidative damages) and the increased oxidative damage causes cell stress, known as oxidative stress [1,2].

Several chronic diseases such as diabetes, neurodegenerative and cardiovascular diseases, and cancer can be caused by increased oxidative stress [3]. This occurs from the activation of various transcription factors, which can express hundreds of different genes, such as growth factor promoters and inflammatory cytokines, which lead to the activation of inflammatory pathways transforming a normal cell into a cancerous one [4].

Thus, maintenance of redox homeostasis and reduction of oxidative stress depend on the efficiency of antioxidant present in the cell, since the first and second defense barriers (antioxidant enzymes and proteolytic and lipolytic enzymes, respectively) have already been overcome [5]. Some enzymes, such as cytochrome P450 (CP450), lipoxygenase (LO), myeloperoxidase (MP), NADPH oxidase (NO) and xanthine oxidase $(\mathrm{XO})$ that are known to generate ROS during the metabolism of arachidonic acid and their inhibitions break the ROS production cycle with the consequent reduction of the oxidative stress and maintenance of redox homeostasis [6]. The increase of the oxidative stress mediated by ROS may lead to the appearance of several diseases, including cancer. Therefore, the search of agents that maintains the balance of redox homeostasis (antioxidants) has an important role in the discovery of molecules that prevent and halt the growth of cancer cells via reduction of the oxidative stress [3-6].

The literature shows that molecular docking has been an important tool for studies of receptor-ligand interaction in the inhibition of enzymes related to antioxidant activity. This technique has clarified doubts and pointed out clarifications about the possible region of the receptor where the activity occurs, what amino acid residues are involved in the interactions and what atoms are directly interacting with the ligand [7].

Molecular docking has aided in the elucidation of the antioxidant mechanism of compounds submitted to biological tests such as new chromeno-carbamodithioates derivatives. These compounds have been evaluated for their antioxidant activity in the cyclooxygenase- 2 enzyme, using the GOLD program to assess the full range of ligand flexibility and the rotational flexibility of selected receptor hydrogens, and the Autodock 4.0 program to check out the binding free energy and inhibition constant (Ki) concerning the interaction of ligands with the receptor [8]. Molecular docking study at the $\operatorname{PPAR} \alpha / \gamma$ receptor has been used to evaluate the agonist and the antioxidant activity of a novel structural class of coumarin-chalcone fibrates using AutoDock 4.2.6 program [9].

As well as molecular docking analysis, significant importance can be attributed to obtaining molecular descriptors and information obtained from chemical-quantum calculations. These data assist in the elucidation of various physical and chemical properties resulting from the different classes of existing compounds [10]. A study on the antioxidant activity of 4-hydroxyphenyl substituted thiopyrimidines has been performed using the Gaussian 9 program to obtain the energies of molecular orbitals (HOMO e LUMO) and evaluation of the electron donor and acceptor character of the chemical species under analysis [11].

In similar studies, the antioxidant activity was evaluated for 1,3,4-thiadiazole derivatives [12] and for major chemical constituents present in the leaves of the Curatella americana Linn [13]. In both studies, molecular descriptors such as the dipole moment, polarizability, chemical hardness/softness, electronegativity and molecular orbital energies have been calculated, analyzed and the results used to evaluate the reactivity and stability of the species studied in relation to antioxidant activity.

In this manuscript, two caffeine analogs of the zinc database ZINC08706191 (Z91) and ZINC08992920 (Z20), proposed by Costa et al. (2018) [14], have been tested in silico to evaluate the antioxidant potential via molecular docking with five enzymes (CP450, LO, MP, NO and XO). They have been compared with known molecules that were used as positive controls, such as: 5-fluorouracil 
(FLU), zileuton (ZIL), melatonin (MEL), dextromethorphan (DEX) and febuxostat (FEB), for each receptor, respectively. Quantum chemical calculations $\left(\mathrm{HF} / 6-31 \mathrm{G}^{* *}\right)$ and Pearson's correlation were performed for compounds studied here.

\section{Results and Discussion}

\subsection{Evaluation of Molecular Docking}

Data about validation protocols for molecular docking can be seen in Figure 1. According to literature, the RMSD values expressing the relationship between the calculated X crystallographic data of the complexed ligand must be less than $2.0 \AA$ [14-16]. The similarity in the overlapping of crystallographic poses (orientation + conformation, cyan) and calculated (yellow) was obtained via molecular docking and graphically displays a low RMSD value, what characterizes good results according to literature (see Figure 1). These results attest that the protocols used can be applied in the molecular docking analyzes between the receptors of the antioxidant activity and ligands.

The binding free energies $(\Delta G)$ for the molecules evaluated at each receptor are shown in Figure 2, and these values were used to classify the best poses obtained in the molecular docking analyses. Only the smallest $\Delta G$ values for the best poses are shown. The larger the peaks, the lower the $\Delta G$ and consequently the more significant the interaction between the receptor and the ligands for the antioxidant ability.

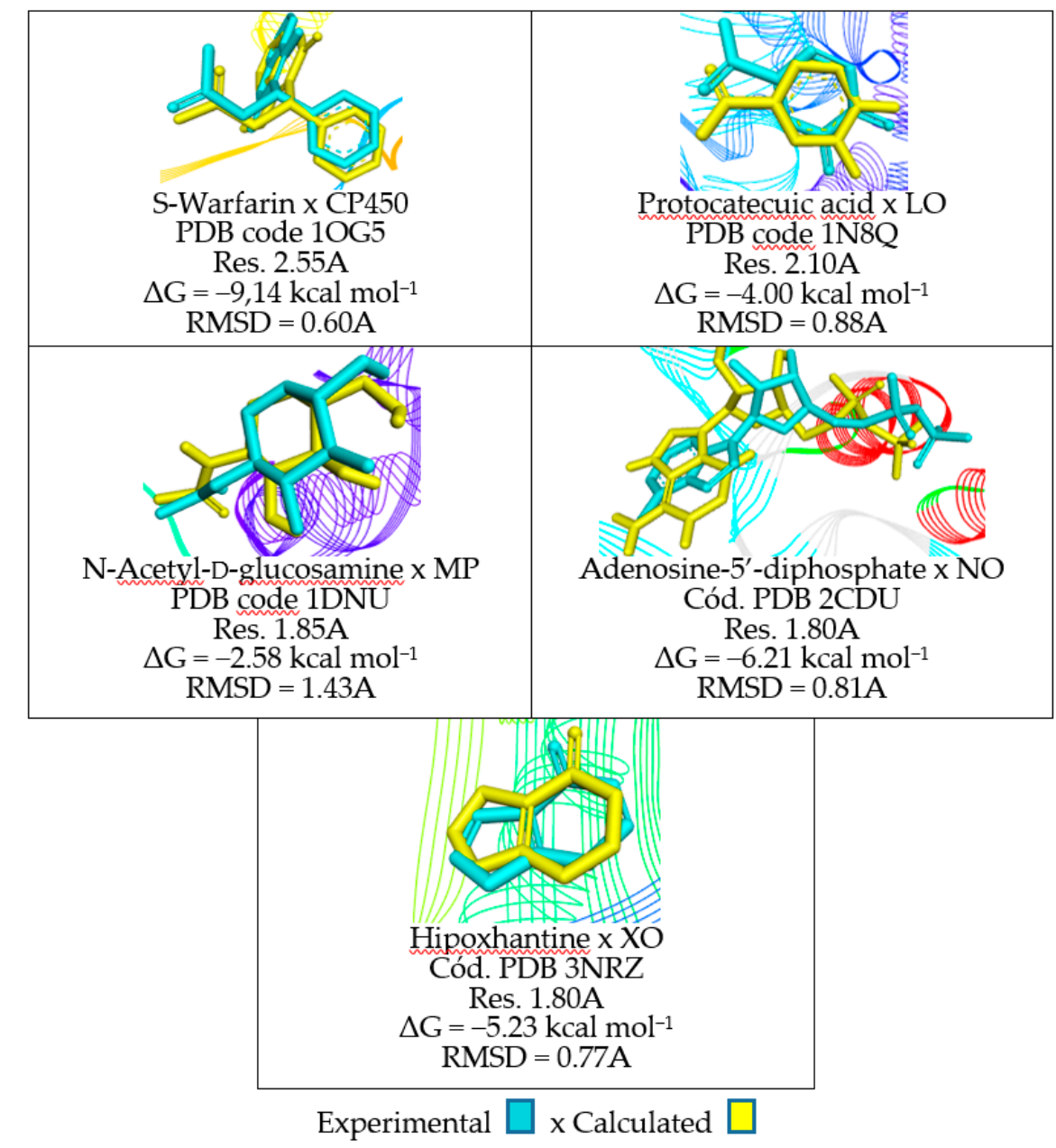

Figure 1. Data obtained in the validation of the molecular docking protocols for the receptors cytochrome P450 (CP450), lypoxygenase (LO), myeloperoxidase (MP), NADPH oxidase (NO) and xanthine oxidase $(\mathrm{XO})$. 


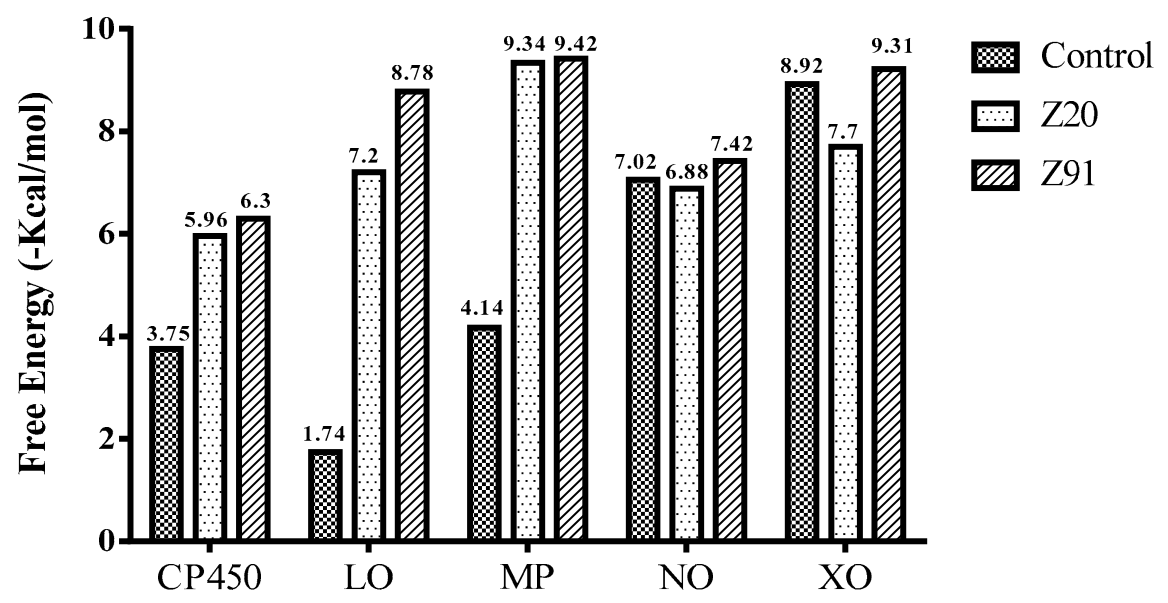

Figure 2. Binding free energy values resulting from the molecular docking between the molecules and receptors evaluated. Control molecules for CP450, LO, MP, NO and XO were 5-fluorouracil (FLU), zileuton (ZIL), melatonin (MEL), dextromethorphan (DEX) and febuxostat (FEB), respectively.

Figure 3 shows binding affinity data values for the selected molecules from the $\Delta G$ values. The tested molecules (Z91 and Z20) showed very similar binding affinity levels at the CP450, MP and NO receptors. The binding affinity values at these three receptors for the molecules tested are higher than control 1 and lower than control 2. The molecules tested had values of non-significant binding affinities (positive- not shown) in the $\mathrm{LO}$ and $\mathrm{XO}$ receptors, and these were excluded to subsequent analyzes.

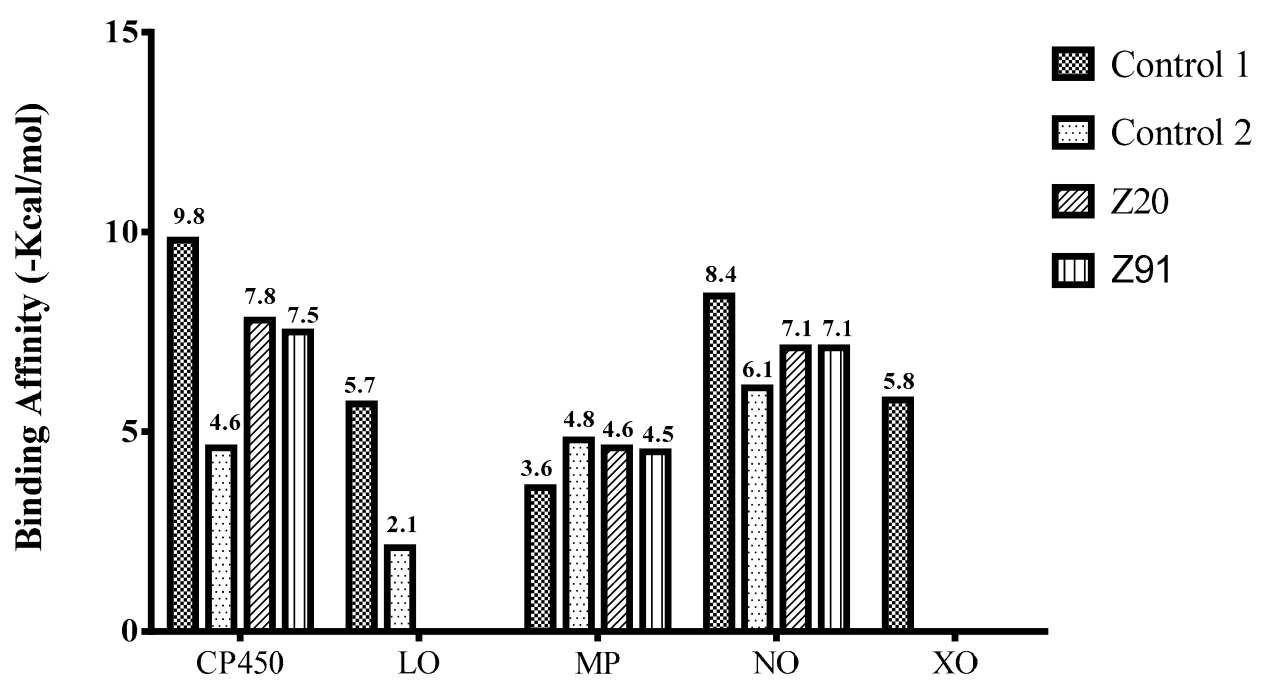

Figure 3. Binding affinity provided by AutoDock/Vina software of the tested molecules (Z20 and Z91). Control 1/Control 2 molecules for CP450, LO, MP, NO and XO were FLU/S-warfarin, $\mathrm{ZIL} /$ protocatechuic acid, MEL/N-acetyl-D-glucosamine, DEX/adenosine-5'-diphosphate and FEB/hypoxanthine, respectively.

Figure 4 shows the interactions data of the tested (Z20 and Z91) and control (FLU) molecules with the CP450 receptor. Five amino acid residues (PRO367, ALA 103, LEU366, PHE 114 and ILE99) were common to Z20, Z91 and FLU (indicated by the blue in diagram A). This shows the degree of correspondence between the control and the molecules tested inferring that these may have potential antioxidant ability. The Z20 and Z91 molecules with lower number of interactions (seven and six, respectively) showed a BA $\left(-7.8 \mathrm{kcal} \mathrm{mol}^{-1}\right.$ and $-7.5 \mathrm{kcal} \mathrm{mol}^{-1}$, respectively) higher than control 1 (FLU) with BA $=-9.8 \mathrm{kcal}^{\mathrm{mol}}{ }^{-1}$ (eight interactions). It is possible to verify the tendency of the BA value to decrease on increasing the number of interactions. 
Additionally, study with CP450 structure complexed with $S$-warfarin shows that the active site of interaction is coated by ARG97, GLY98, ILE99, PHE100, LEU102, ALA103, VAL113, PHE114, ASN217, THR364, SER365, LEU366, PRO367 and PHE476 residues. Specific interactions occur between some of these residues and the phenyl group of $S$-warfarin (control 2), which bundles against the side chains of PHE476 (pi-pi interaction), PHE100 and ALA103 (hydrogen bond) and interact with PRO367 too [17]. Figure 4 displays a high similarity of interactions with the CP450 receptor between the tested and control molecules, and findings of the literature [17]. These results for the tested molecules together to good BA values (differences of $-2.0 \mathrm{kcal} \mathrm{mol}^{-1}$ in $\mathrm{Z20}$ and $-2.3 \mathrm{kcal} \mathrm{mol}^{-1}$ in Z91, in relation to the FLU control) indicate a good antioxidant ability to these molecules.

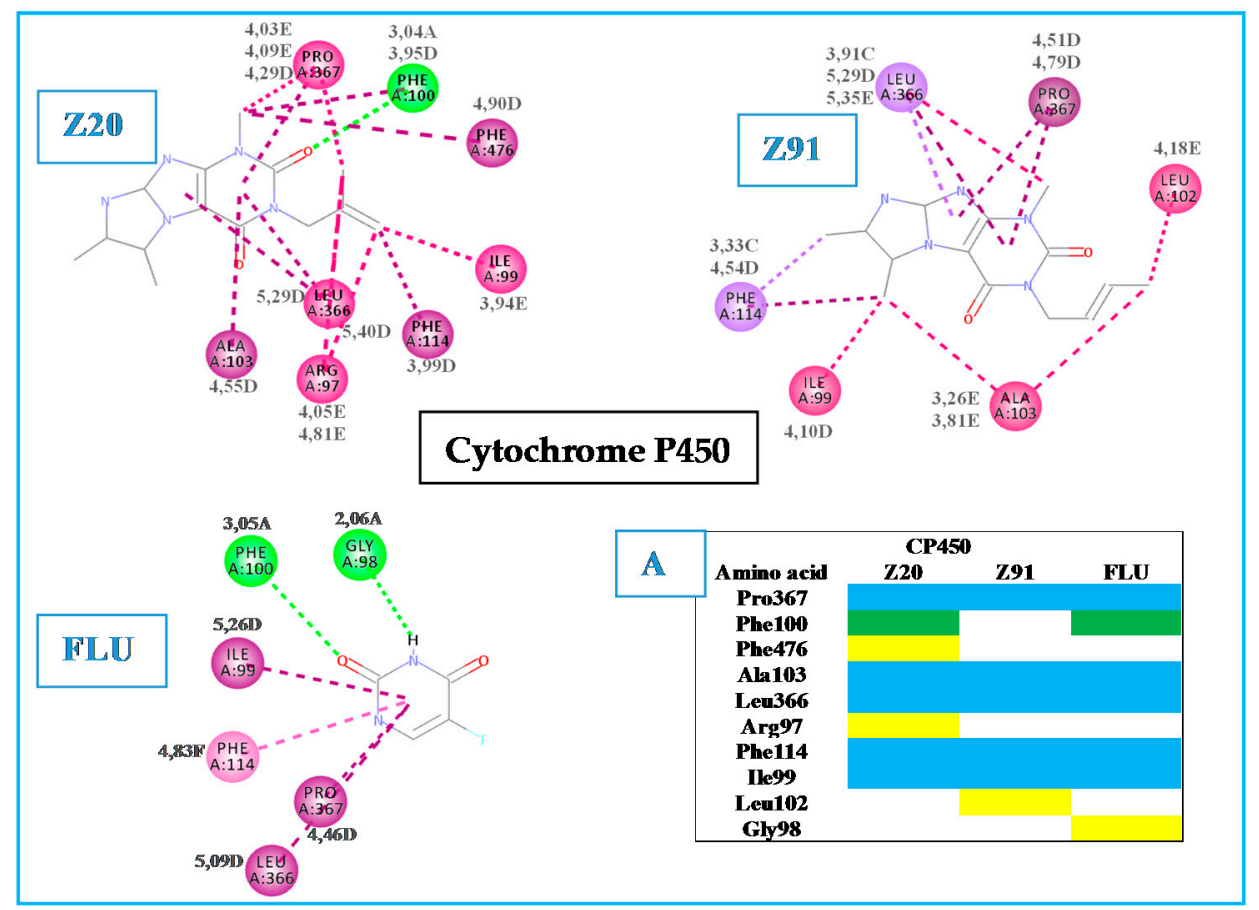

Figure 4. Interactions of the tested molecules (Z20 and Z91) and control (FLU) with the CP450 receptor. In $\mathrm{A}$, interactions common to the three ligands (blue), two ligands (green) and interactions presented by a single ligand (yellow) are presented. Hydrogen bond (A); carbon-hydrogen bond (B); pi-sigma (C); $\square$ pi-alkyl (D); $\square$ alkyl (E).

In the MP receptor (Figure 5), a maximum of six interactions were observed. In the PDB file (1DNU) [18] the active site of attachment has its location pointed out to the ASN192, GLN201 and VAL199 amino acid residues, which interact with the ligand $N$-acetyl-D-glucosamine. This ligand is complexed with the MP receptor available in the PDB (control 2, Figure 3). The three previously mentioned residues interact with the control molecule, MEL and two of them (GLN201 and VAL199) interact with Z20 and Z91, which indicates a reasonable antioxidant ability to the molecules tested. Other indications of good antioxidant ability are the similarities with the control molecule: Z20 and Z91 interact with four amino acid residues (blue in diagram A of Figure 5) common to the control and BA values lower than that of the control (-4.6 kcal mol ${ }^{-1}$ for Z20, $-4.5 \mathrm{kcal} \mathrm{mol}^{-1}$ for Z91 and $-3.6 \mathrm{kcal} \mathrm{mol}^{-1}$ for the MEL control).

In NO (see Figure 6) the ASP179 residue only showed interaction with all molecules (blue in diagram A). For this receptor an increase in the number of interactions provided an increase in the BA value, when compared to Z91 (eight interactions and BA $=-7.1 \mathrm{kcal}^{\mathrm{mol}}{ }^{-1}$ ), and with DEX control (three interactions and $\mathrm{BA}=-8.4 \mathrm{kcal}_{\mathrm{mol}} \mathrm{mo}^{-1}$ ). These BA values are relatively close (difference of $-1,3 \mathrm{kcal} \mathrm{mol}^{-1}$ for Z20 and Z91) to the DEX control, which indicates a good antioxidant ability of the tested molecules in the NO receptor. 
Another evidence of this antioxidant ability is the similarity of the interactions and of the active site with results obtained from the literature [19]. In such study, the active site is surrounded by ILE160, ILE243, ASP179, LYS213, VAL214 and TYR188 residues, which interact with the ligand adenosine-5'-diphosphate (Control 2 in the NO receptor-Figure 3). From the list of residues, four interact with Z91 (ILE243, ASP179, LYS213 and VAL214), three with Z20 (ILE243, ASP179 and TYR188) and one with the DEX control (ASP179).

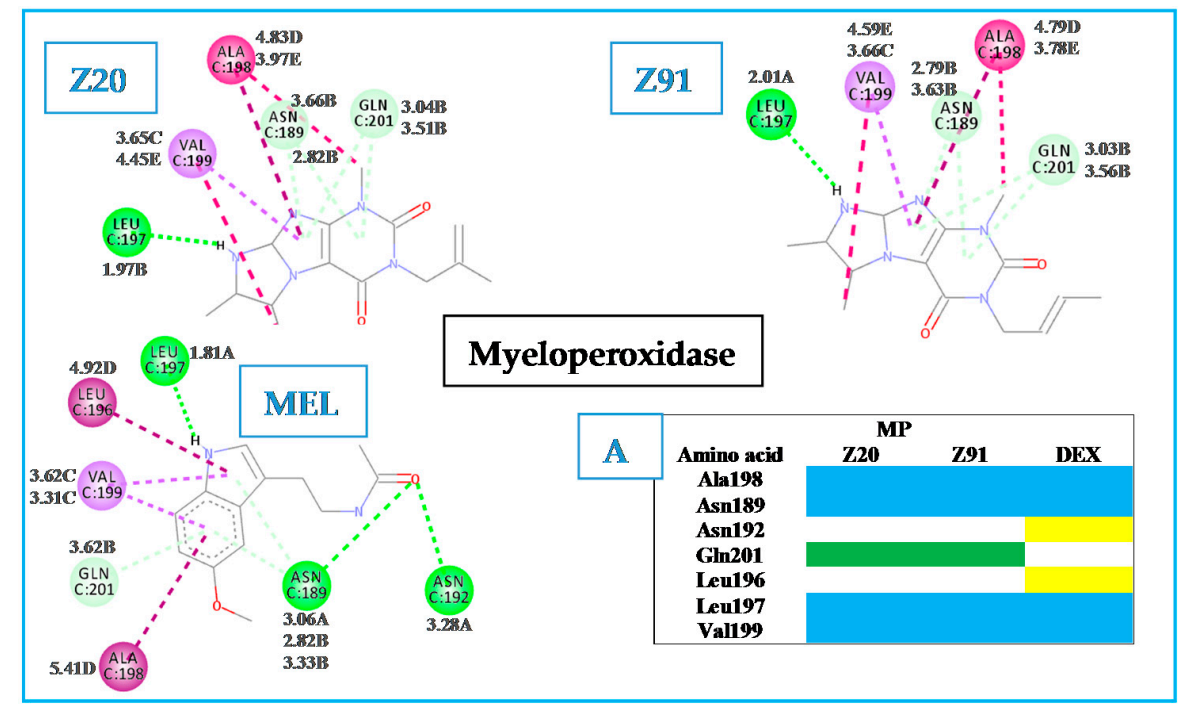

Figure 5. Interactions of the tested molecules (Z20 and Z91) and control (MEL) with the MP receptor. In $\mathrm{A}$, interactions common to the three ligands (blue) and two ligands (green). Hydrogen bond (A); carbon-hydrogen bond (B); pi-sigma (C); $\square$ pi-alkyl (D); $\square$ alkyl (E).

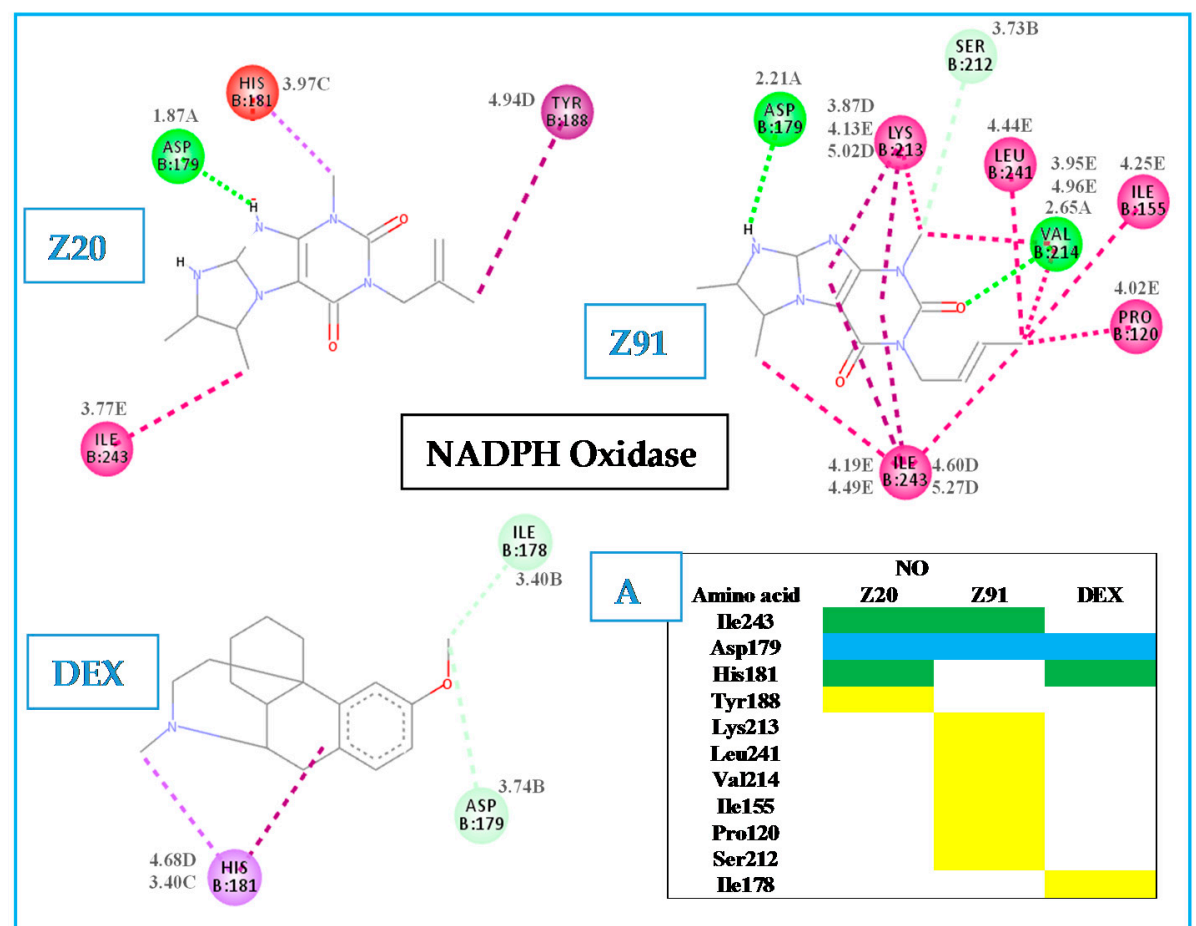

Figure 6. Interactions of the tested molecules (Z20 and Z91) and control (DEX) with the NO receptor. In $\mathrm{A}$, interactions common to the three ligands (blue), two ligands (green) and interactions presented by a single ligand (yellow) are presented. Hydrogen bond (A); carbon-hydrogen bond (B); pi-sigma (C); pi-alkyl (D); $\square$ akyl (E). 
The antioxidant abilities of the control molecules may be related to the amino acid residues with which molecules interact. For this reason, the observation of the common residues and BA values close to the tested molecules, controls and literature infer that the tested molecules can have a good antioxidant ability. This relationship is very evident for both Z20 and Z91 that have high similarity in the presented characteristics (among themselves, compared to controls and BA values). This can be explained by the high structural similarity of Z20 and Z91, with evident difference only in the four-carbon radical connected to nitrogen, showing that the alkenyl group (Z91) and the vinyl group are attached to the second carbon of radical (Z20, see Table 1).

Table 1. Structure of the tested molecules used for in silico evaluation of the antioxidant potential.

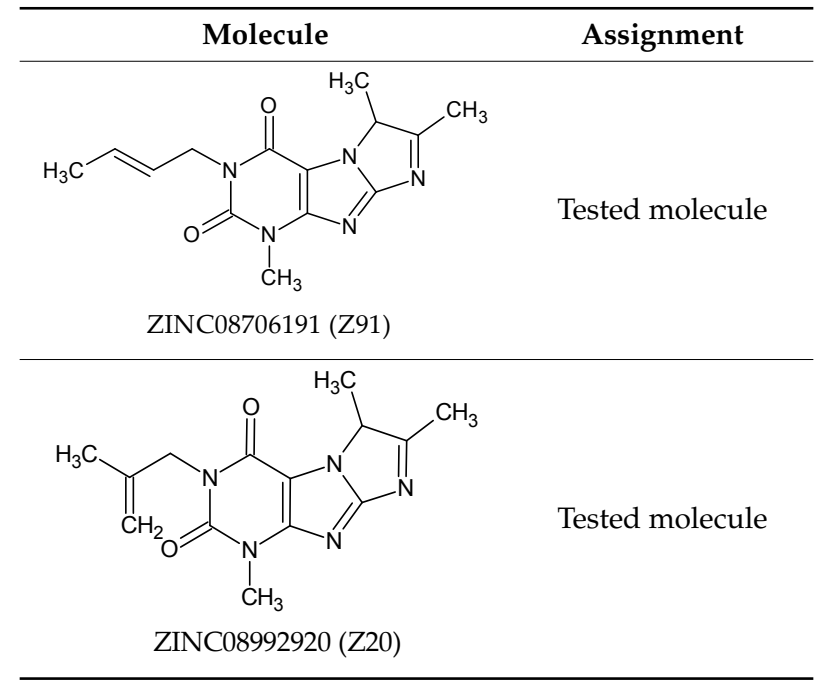

\subsection{Molecular Descriptors and Pearson Correlations}

Table 2 shows the data of the molecular descriptors and correlations with the Ki values for the three receptors analyzed (CP450, MP and NO). Ki (inhibition constant) is the concentration of the inhibitor needed to reduce the activity of the receptor by half. It reflects the binding affinity of the inhibitor with a specific receptor. The lower Ki value, the smaller the amount of inhibitor needed to reduce the reaction rate (inhibit the reaction) and the better the binding affinity [20]. The tested molecules Z20 and Z91 presented lower Ki values than the control molecules, which proves good antioxidant abilities for the tested molecules.

The molecular descriptors presented reasonable results of correlations with the Ki values (between 0.65 and 0.99) for all descriptors in the $\mathrm{CP} 450$ receptor. Already the NO receptor presented four significant correlations (between 0.48 and 0.74 ), while the MP receptor had two significant correlations (both 0.60 ). Relatively low correlation values may be considered non-significant according to the literature [21,22]. This shows that some of these descriptors have significant relation (values in bold) with the Ki values, (Table 2), reaffirming again the notable antioxidant ability.

Total surface area (TSA) of a molecule is related to its solubility and the molecular interaction that it can performed due to the superficial contact with other molecules [23]. Similar analysis can be done for the molar volume (MV), because the higher the TSA and MV, the higher the level of interaction. From TSA and MV the intermolecular forces operate, giving rise to the energy of molecular interaction [24]. The Ki values showed significant and negative correlations with TSA and MV only in CP450 and NO, indicating that the increase in these descriptors values is important for the Ki to decrease (increased antioxidant ability) in the mentioned receptors.

Molecules formed by different atoms have a polar covalent bond that can be quantified by a dipole moment. This is described with a positive partial charge close to a negative partial charge of the same absolute value, and the measure of the magnitude of these charges is given in Debyes (D). In the case of polyatomic molecules, a total dipole moment (TDM) is observed. The higher the TDM, the greater 
the polarity of the molecule and consequently greater a tendency to dissolve and interact in polar environment $[25,26]$. The electronegativity $(\chi)$, is directly related to TDM, and is described as the capacity that an atom has to attract to itself electrons of a bond that it makes with another atom [27]. It can be used to estimate the tendency of a molecule to attract electrons from another molecule with which it performs interaction [28].

Table 2. Molecular descriptors of the tested (Z20 and Z91) and reference molecules (5-fluorouracil-FLU, melatonin-MEL and dextromethorphan) and their correlations (CKi-CP450, CKi-MP and CKi-NO) with Ki values resulting from the molecular docking study.

\begin{tabular}{cccccc}
\hline Descriptors & Z91 & Z20 & FLU & MEL & DEX \\
\hline $\mathrm{AST}\left(\AA^{2}\right)$ & 457.6300 & 432.0800 & 229.5500 & 438.0500 & 371.1200 \\
$\mathrm{MV}\left(\AA^{3}\right)$ & 831.4000 & 817.9600 & 348.7100 & 740.5100 & 821.6600 \\
$\chi(\mathrm{eV})$ & 2.9553 & 2.9776 & 3.5946 & 1.9003 & 1.9594 \\
\hline$\eta(\mathrm{eV})$ & 5.2982 & 5.3058 & 6.3539 & 5.4811 & 5.9292 \\
$1 / \eta(\mathrm{eV})$ & 0.1887 & 0.1885 & 0.1574 & 0.1824 & 0.1687 \\
$\mu(\mathrm{eV})$ & -2.9553 & -2.9776 & -3.5946 & -1.9003 & -1.9594 \\
$\mathrm{Ki}-\mathrm{CP} 450(\mu \mathrm{M})$ & 24.30 & 17.89 & 182.0 & - & - \\
$\mathrm{Ki}-\mathrm{MP}(\mu \mathrm{M})$ & 22.58 & 19.97 & - & 185.0 & - \\
$\mathrm{Ki}-\mathrm{NO}(\mu \mathrm{M})$ & 9.83 & 3.36 & - & - & 7.11 \\
\hline $\mathrm{Descriptors}$ & $\mathrm{CKi}-\mathrm{CP450}$ & $\mathrm{CKi}-\mathrm{MP}$ & $\mathrm{CKi}-\mathrm{NO}$ & - & - \\
\hline $\mathrm{AST}$ & -0.95 & -0.28 & -0.51 & - & - \\
$\mathrm{VM}$ & -0.99 & -0.05 & -0.74 & - & - \\
$\chi$ & -0.67 & -0.60 & -0.08 & - & - \\
$\eta$ & 0.85 & 0.19 & 0.49 & - & - \\
$1 / \eta$ & -0.83 & -0.17 & -0.48 & - & - \\
$\mu$ & -0.67 & -0.60 & -0.08 & - &
\end{tabular}

$\AA$ A Angstrom; $\mathrm{eV}=$ eletron volt. Significant data at $p<0.05$.

The Ki values showed significative negative (inversely proportional) correlations with $\chi$ only the CP450 and MP receptors. The $\chi$ values increase with the Ki values to decrease. An increase in the $\chi$ promotes an increase in the polarity with consequent increase in attractive forces (between receptor and other amino acid residues) in certain regions providing better receptor-ligand interaction- $\mathrm{Ki}$ (good binding affinity for antioxidant ability).

The molecular hardness $(\eta)$ and softness $(1 / \eta)$ also are important parameters that describe the reactivity of a molecule. The softness is related to basicity and to electron donation with high polarizability and low electronegativity, besides favoring the molecular flexibility with consequent chemical reactivity [29-31]. The hardness is already characterized by high ionization potential and high electronegativity, favoring the molecular stiffness with consequent chemical stability [32,33].

The descriptors $\eta$ and $1 / \eta$ presented significant values of Ki knockouts only at CP450 and $\mathrm{NO}$ receptors. In these receptors the $1 / \eta$ values presented negative correlations with $\mathrm{Ki}$, while the correlations between $\eta$ and Ki were positive. Decrease of Ki with increase of the softness and decrease of the hardness, indicates the reactivity of the tested molecules and their contribution to the antioxidant ability (significant correlations with $\mathrm{Ki}$ ).

Chemical potential $(\mu)$ of a species is expressed as a function of thermodynamic quantities. And it can be described as a form of energy absorbed or released from a chemical reaction or change of state. It is related to free energy, binding affinity and inhibition constant, being influenced by the number of atoms or molecules that are added or subtracted from the system [34-36]. Negative values of correlation between $\mu$ and Ki were significant only for CP450 and MP. These negative values show that the higher the values of $\mu$, the lower the Ki values (higher values of $\mu$ favor the antioxidant ability). The tested molecules presented values of $\mu$ close to those of the control molecules, favoring the antioxidant ability in the two mentioned receptors. 


\subsection{Molecular Orbitals and Characteristic of Antioxidant Ability}

Table 3 shows data and representations of the molecular orbitals, GAP values (energy variation between frontier orbitals) between all the energy states $\mathrm{GAP}_{1}, \mathrm{GAP}_{2}, \mathrm{GAP}_{3}$ and $\mathrm{GAP}_{4}$. The molecular orbitals LUMO and LUMO +1 have a direct relation with the electron affinity of a molecule, which is related to susceptibility to nucleophilic attacks [37]. The values of LUMO and LUMO+1 for Z91 and $\mathrm{Z} 20$ were close to those of the control molecules. This show that Z91 and Z20 are less susceptible to attack by nucleophiles. The values of LUMO and LUMO+1 were positively correlated with the Ki values. Only CP450 receptors (0.91 for LUMO and 0.88 for LUMO+1) and MP (0.54 for LUMO and 0.60 for $\mathrm{LUMO}+1$ ) showed significant correlation values, revealing the tendency of the Ki values to decrease with the reduction of LUMO and LUMO+1 values for these receptors.

Table 3. Representations of the molecular orbitals and their GAP values (energy variation between frontier orbitals-HOMO and LUMO) between all energy states $\left({ }^{[a]} \mathrm{GAP}_{1},{ }^{[\mathrm{b}]} \mathrm{GAP}_{2},{ }^{[\mathrm{c}]} \mathrm{GAP} 3\right.$ and ${ }^{[\mathrm{d}]}$ GAP4) of the Z20, Z91, 5-fluorouracil (FLU), melatonin (MEL) and dextromethorphan (DEX).

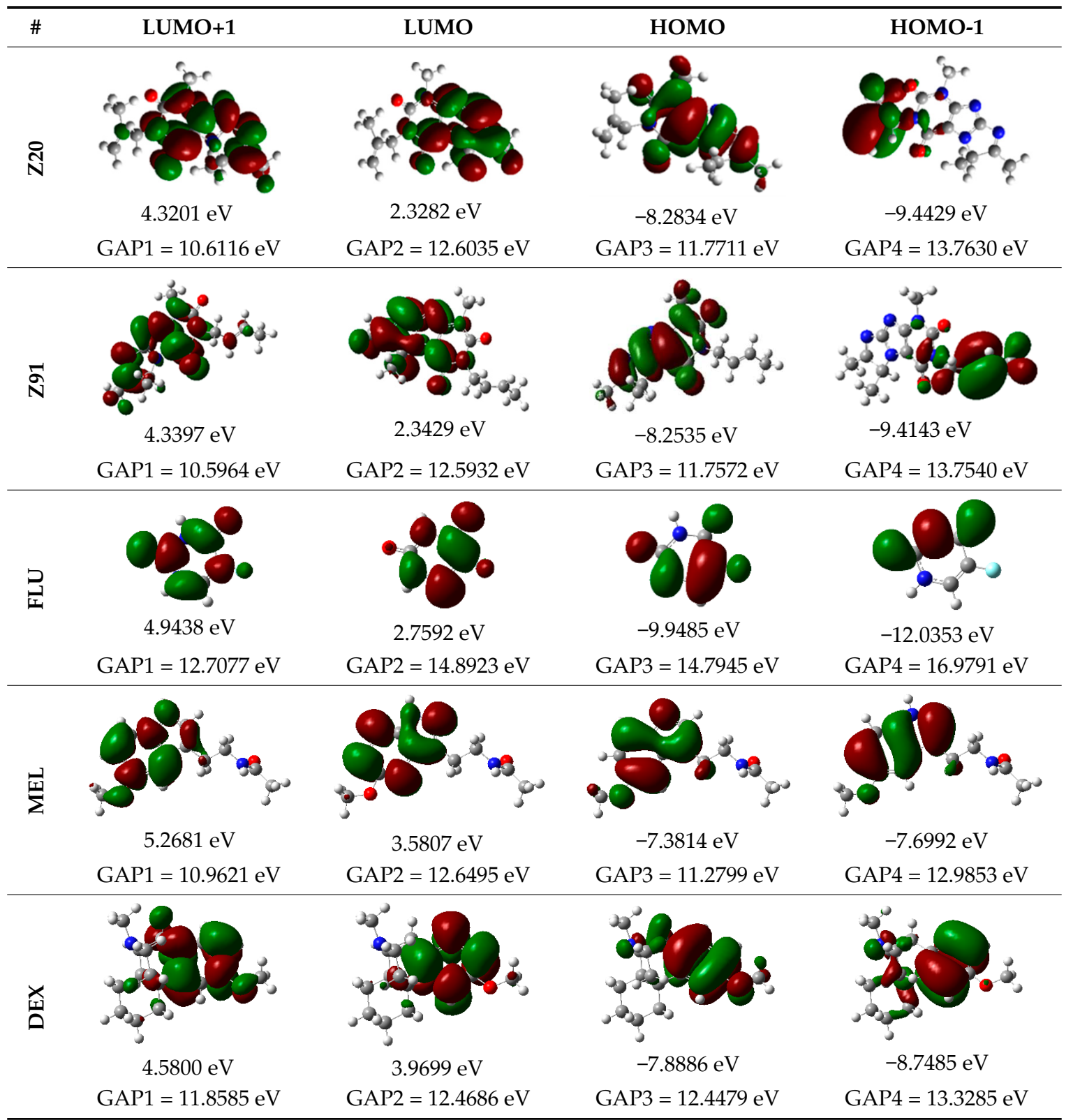

${ }^{[\mathrm{a}]} \mathrm{GAP} 1$ = LUMO $-\mathrm{HOMO} ;{ }^{[\mathrm{b}]}$ GAP2 = LUMO+1 - HOMO; ${ }^{[\mathrm{cc}}$ GAP3 =LUMO $-\mathrm{HOMO}-1$; ${ }^{[\mathrm{d}]}$ GAP4 = LUMO+1 - HOMO-1. 
Significant correlation values with Ki were obtained for molecular orbital data (see Table 4). The HOMO orbital showed a significant correlation with $\mathrm{Ki}$ only in the MP receptor (0.47) and the HOMO-1 orbital only in MP (0.81) and NO (0.92). The energies of the HOMO and HOMO-1 molecular orbitals are strongly related to the ionization potential of a molecule and are indicative of the nucleophilic character of the species [38-40]. The results for HOMO (MP) and HOMO-1 (MP and NO) presented by Z91 and Z20 were close to those of the control molecules. These data show that as well as the control molecules, Z91 and Z20 have a higher electron donor character and greater ability to perform nucleophilic attacks. The negative correlations between HOMO and HOMO-1 orbitals and Ki values attest to the inversely proportional relation of these variables, with a decrease in Ki values from the increase in HOMO and HOMO-1 values. These results attest to the strong relationship of the molecular orbitals data with the Ki values (in this study representing the characteristic of antioxidant ability).

The energy variation between the HOMO and LUMO orbitals is called the GAP. GAP is an important indicator of the chemical reactivity of a molecule. The lower GAP values the greater chemical reactivity of the molecule and higher values the greater stability [41]. According to studies carried out by Fujishima et al. molecules with antioxidant potential are less stable and therefore, more reactive, i.e., a large gap implies a good thermodynamic stability of the compound, whereas a small gap suggests an easy electronic transition [13].

By evaluating the four calculated GAP values (GAP's 1-4) for each molecule, it is possible to observe low values for Z91 and Z20 compared to the control compounds reinforcing our results in the molecular docking study (see Tables 4 and 5). Therefore, these results show that all molecules have significant chemical reactivity, necessary for interaction with receptors.

Table 4. Correlations between molecular orbitals data and Ki values.

\begin{tabular}{cccc}
\hline \multirow{2}{*}{ Descriptors } & \multicolumn{3}{c}{ Enzymes } \\
\cline { 2 - 4 } & $\mathbf{C P 4 5 0}$ & MP & NO \\
\hline HOMO-1 $(\mathrm{eV})$ & -0.38 & -0.81 & -0.92 \\
HOMO $(\mathrm{eV})$ & -0.13 & -0.47 & -0.22 \\
LUMO $(\mathrm{eV})$ & 0.91 & 0.54 & 0.30 \\
LUMO+1 $(\mathrm{eV})$ & 0.88 & 0.60 & 0.23 \\
\hline
\end{tabular}

An important evidence (see Table 5) is related to the negative values (in bold) of variations of GAP values ( $\triangle \mathrm{GAP}$ ) between the tested and control molecules. These negative values indicate that the GAP values of the molecules tested are lower than the control molecules, pointing out to the higher reactivity of the molecules tested with the $\triangle G A P$ values highlighted. This indicates that the antioxidant ability of Z20 and Z91 can be influenced by the four values of GAPs evaluated (transition states 1-4) in the CP450 receptor, by the GAP1 and GAP2 (transition states 1 and 2) in the MP receptor and by GAP1 and GAP3 (transition states 1 and 2) in the NO receptor.

Table 5. Variations of GAP values compared to controls.

\begin{tabular}{ccccc}
\hline$\Delta$ GAP & GAP1 * & GAP2 * & GAP3 & GAP4 \\
\hline$\Delta$ GAP (Z20-FLU) & -2.0961 & -2.2888 & -3.0234 & -3.2161 \\
$\Delta$ GAP (Z91-FLU) & -2.1113 & -2.2991 & -3.0373 & -3.2251 \\
$\Delta$ GAP (Z20-MEL) & -0.3505 & -0.3586 & 0.4912 & 0.7777 \\
$\Delta$ GAP (Z91-MEL) & -0.3657 & -0.3689 & 0.4773 & 0.7687 \\
$\Delta$ GAP (Z20-DEX) & -1.2469 & 0.1349 & -0.6768 & 0.4345 \\
$\Delta$ GAP (Z91-DEX) & -1.2621 & 0.1246 & -0.6907 & 0.4255 \\
\hline \multicolumn{5}{r}{ * Tested molecule GAP_Control GAP. }
\end{tabular}




\section{Materials and Methods}

\subsection{Calculation of Receptor-Ligand Interaction for Evaluation of Antioxidant Potential}

Initially, five enzymes (receptors) that respond for the production of reactive oxygen species (ROS) during the metabolism, cytochrome P450 (CP450), lypoxygenase (LO), myeloperoxidase (MP), NADPH oxidase (NO) and xanthine oxidase $(\mathrm{XO})$ were selected and obtained from the Protein Data Bank (PDB) [42]. $\Delta \mathrm{G}$ values, Receptor-ligand interaction data (binding affinity-BA) and inhibition constant (Ki) values regarding the inhibition of these receptors were obtained in the Autodock 4.2.6/Vina programs [43], respectively, based on standard protocol established by our research group for each analyzed receptor [13,44-47].

Molecules with positive binding affinity values were not shown, and only molecules with negative binding affinity values were analyzed. A maximum cutoff value of $5.5 \AA$ was adopted for the lengths of receptor-ligand interactions [48]. Table 6 shows the protocols used in the validation and subsequent docking analyses of each receptor. The calculations were performed with default parameters by the genetic algorithm, following the protocol described by Pereira et al. and Padilha et al. [49,50].

A total of seven molecules were docked in the five receptors cited, according to Tables 1 and 7. Caffeine analogs have shown potential inhibitory effect against epithelial cancer according to studies Rogozin et al. [51] that related to the prevention of Epidermal Growth Factor (EGF) in the malignant transformation of epidermal cells of susceptible JB6 rats $(\mathrm{P}+)$ C141 (JB6 P+). In the study carried out by Costa et al. [14], in silico simulations new caffeine-based molecules with potential epithelial anticancer activity have been proposed from the zinc database by virtual screening (ZINC08706191 and ZINC08992920).

Table 6. Data from protocols used in the molecular docking validation.

\begin{tabular}{|c|c|c|c|}
\hline Receptor & Ligand & Coordinates of the Grid Center & Grid Size (points) \\
\hline \multirow{3}{*}{$\begin{array}{c}\text { CP450 } \\
\text { (PDB code: } 1 \text { OG5) }\end{array}$} & \multirow{3}{*}{$S$-Warfarin } & $-20.257 x$ & $22 x$ \\
\hline & & $86.991 y$ & $20 \mathrm{y}$ \\
\hline & & $38.581 z$ & $24 \mathrm{z}$ \\
\hline \multirow{3}{*}{$\begin{array}{c}\text { LO } \\
\text { (PDB code: 1N8Q) }\end{array}$} & \multirow{3}{*}{ Protocatecuic acid } & $21.864 x$ & $24 x$ \\
\hline & & $2.184 y$ & $18 \mathrm{y}$ \\
\hline & & $18.909 \mathrm{z}$ & $12 \mathrm{z}$ \\
\hline \multirow{3}{*}{$\begin{array}{c}\text { MP } \\
\text { (PDB code: 1DNU) }\end{array}$} & \multirow{3}{*}{ N-Acetyl-D-glucosamine } & $39.817 x$ & $22 x$ \\
\hline & & $-38.635 y$ & $30 \mathrm{y}$ \\
\hline & & $-5.308 \mathrm{z}$ & $18 \mathrm{z}$ \\
\hline \multirow{3}{*}{$\begin{array}{c}\text { NO } \\
\text { (PDB code: } 2 \mathrm{CDU})\end{array}$} & \multirow{3}{*}{ Adenosine-5'-diphosphate } & $1.687 x$ & $30 x$ \\
\hline & & $9.885 y$ & $14 \mathrm{y}$ \\
\hline & & $54.962 \mathrm{z}$ & $32 \mathrm{z}$ \\
\hline \multirow{3}{*}{$\begin{array}{c}\text { XO } \\
\text { (PDB code: 3NRZ) }\end{array}$} & \multirow{3}{*}{ Hypoxanthine } & $89.018 x$ & $37 x$ \\
\hline & & $9.4501 y$ & $37 \mathrm{y}$ \\
\hline & & $18.290 \mathrm{z}$ & $37 \mathrm{z}$ \\
\hline
\end{tabular}

The two caffeine analogs used in this in silico study were ZINC08706191 (Z91) and ZINC08992920 (Z20), because the intracellular productions of ROS, which are associated with many cellular events including activation of enzymes [13] and cancer, may be caused by increased oxidative stress mediated by ROS [3-6]. The inappropriate scavenging of these ROS or enzymatic inhibition can result in degradation of protein, lipid peroxidation, and DNA oxidation, which have been related to skin inflammatory disorders, chronic diseases such as cancer and atherosclerosis besides contributing with the development of degenerative diseases [52-54]. 
Table 7. Structure of the controls molecules used for in silico evaluation of the antioxidant potential.

Molecule (control) present in commercially available drug with
inhibitory activity at the $\mathrm{CP} 450$ receptor [55,56].<smiles>COc1ccc2c(c1)C13CCCCC1CN(C)CC2C3</smiles>

Molecule (control) present in commercially available drug with inhibitory activity at the NO receptor $[56,61,62]$.

Dextromethorphan (DEX)<smiles>Cc1nc(-c2ccc(OCC(C)C)c(C#N)c2)sc1C(=O)O</smiles>

Molecule (control) present in commercially available drug with inhibitory activity at the $\mathrm{XO}$ receptor $[13,56,63]$.

Febuxostat (FEB)

\subsection{Quantum Chemical Calculations}

Calculations to obtain molecular descriptors data were performed in vacuum in the Gaussian 09 program for the molecules under study. The method used was the Hartree-Fock in the 6-31G** basis set $\left(\mathrm{HF} / 6-31 \mathrm{G}^{* *}\right)$. The choice of this method was based on the study of Costa et al. (2018) [64], who classified the HF/6-31G** method as the best method for the molecular modeling of caffeine and analogues. The descriptors obtained from calculations were the following: total surface area, molar volume, total dipole moment; molecular hardness $(\eta)$, molecular softness $(1 / \eta)$, electronegativity $(\chi)$, chemical potential $(\mu)$, highest occupied molecular orbital energy (HOMO), a level of energy below the highest occupied molecular orbital (HOMO-1), the lowest non-occupied molecular orbital energy (LUMO), and a level of energy above the lowest unoccupied molecular orbital (LUMO+1). GAP values (energy variation between frontier orbitals) were calculated for the four orbitals cited: GAP1 $=$ LUMO - HOMO; GAP2 = LUMO+1 - HOMO; GAP3 = LUMO - HOMO-1; GAP4 = LUMO+1 - HOMO-1.

These data were analyzed and evaluated in relation to their contribution to the antioxidant potential of the tested molecules. Pearson correlation analyzes between the molecular descriptors and 
Ki values for the studied molecules and the receptors evaluated were performed by the Statistica 6.2 program [65]. Only descriptors with significant values of Ki correlation were shown.

\section{Conclusions}

The study of the antioxidant ability of this article was started from crystallographic data of biological receptors of the said activity available in the Protein Data Bank. These data were important initially to validate the docking protocols of the studied molecules (Z20, Z91, FLU, MEL and DEX). The molecular docking protocols for the five receptors (CP450, MP, LO, NO and XO) were all validated by having RMSD (experimental $x$ theoretical) values lower than $2.0 \AA$. This allows the certainty that the theoretical data have good agreement with the experimental data.

The binding affinity (BA) was evaluated for poses with lower $\Delta \mathrm{G}$ values. The $\mathrm{LO}$ and $\mathrm{XO}$ receptors presented positive values of BA and were excluded from the subsequent analyzes. The excellent correspondence of the negative BA values and the lower Ki values (for the CP450, MP and NO receptors) and the interactions of the molecules Z20 and Z91 in relation to the control molecules and findings of the literature, show good antioxidant ability to the tested molecules.

The highest values of TSA, MV, $\chi$ and $1 / \eta$ for Z91 and Z20, show that larger surface areas and volumes result in a greater number of interactions. Higher electronegativities and $1 / \eta$ allow these molecules greater capacity to attract electrons from the interactions with the amino acid residues and greater flexibility to twist and adapt to the receptor active site, with a consequent decrease in the Ki values. The lowest values of $\eta$ and $\mu$, suggest that Z91 and Z20 have a good charge distribution resulting in medium polarity, low stiffness and relationship with thermodynamic properties relative to the quantities of atoms involved in the interactions, and as a consequence also the Ki decrease.

The values of the energies obtained for the molecular orbitals HOMO-1, HOMO, LUMO and LUMO+1 and GAP values, allow the assignment of a strong nucleophilic character (resulting in low Ki values) and high reactivity) to the analyzed molecules (mainly, Z91 and Z20).

The results obtained in this study reveal that Z91 and Z20 have potential antioxidant ability in at least three receptors (CP450, MP and NO) via ROS generation. Thus, Z91 and Z20 may be used for more analyses in order to further evaluate their efficiency in the reduction of oxidative stress and as possible antioxidant to be used in the pharmaceutical industry.

Author Contributions: Conceptualization, R.d.S.B.; Data curation, J.d.S.C.; Formal analysis, K.d.S.L.C. and R.d.S.R.; Investigation, J.d.S.C.; Methodology, J.d.S.C.; Project administration, J.d.S.C., W.J.d.C.M. and C.B.R.d.S.; Resources, D.d.S.B.B. and E.F.B.F.; Software, C.B.R.d.S.; Supervision, J.d.S.C., W.J.d.C.M. and C.B.R.d.S.; Validation, C.B.R.d.S.; Visualization, K.d.S.L.C. and R.d.S.R.; Writing—original draft, J.d.S.C.; Writing一review \& editing, J.d.S.C., C.B.R.d.S., C.H.T.d.P.d.S. and J.M.C.

Funding: This research received no external funding.

Acknowledgments: We acknowledge the Postgraduate Program in Biodiversity and Biotechnology of Amazon (PPG-Bionorte), Paraense Museum Emilio Goeldi (MPEG). Laboratory of Molecular Modeling and Simulation System of Federal Rural University of Amazônia (UFRA-Brazil) and Laboratory of Modeling and Computational Chemistry of Federal University of Amapá by computational and methodological support. Finally, financial support provided by the PROPESP/UFPA is greatly acknowledged.

Conflicts of Interest: The authors declare no conflict of interest.

\section{References}

1. Silva, A.A.; Gonçalves, R.C. Reactive oxygen species and the respiratory tract diseases of large animals. Ciência Rural 2010, 40, 994-1002. [CrossRef]

2. Yun, J.; Mullarky, E.; Lu, C.; Bosch, K.N.; Kavalier, A.; Rivera, K.; Roper, J.; Chio, I.I.; Giannopoulou, E.G.; Rago, C.; et al. Vitamin C selectively kills KRAS and BRAF mutant colorectal cancer cells by targeting GAPDH. Science 2015, 350, 1391-1396. [CrossRef] [PubMed] 
3. White, P.A.; Oliveira, R.C.; Oliveira, A.P.; Serafini, M.R.; Araújo, A.A.; Gelain, D.P.; Moreira, J.C.; Almeida, J.R.; Quintans, J.S.; Quintans-Junior, L.J.; et al. Antioxidant activity and mechanisms of action of natural compounds isolated from lichens: A systematic review. Molecules 2014, 19, 14496-14527. [CrossRef] [PubMed]

4. Reuter, S.; Gupta, S.C.; Chaturvedi, M.M.; Aggarwal, B.B. Oxidative stress, inflammation, and cancer: How are they linked? Free Radic. Biol. Med. 2010, 49, 1603-1616. [CrossRef] [PubMed]

5. Cadenas, E. Basic mechanisms of antioxidant activity. BioFactors 1997, 6, 391-397. [CrossRef] [PubMed]

6. Dharmaraja, A.T. Role of reactive oxygen species (ROS) in therapeutics and drug resistance in cancer and bacteria. J. Med. Chem. 2017, 60, 3221-3240. [CrossRef] [PubMed]

7. Gupta, M.; Sharma, R.; Kumar, A. Docking techniques in pharmacology: How much promising? Comp. Biol. Chem. 2018, 76, 210-217. [CrossRef] [PubMed]

8. Bandari, S.K.; Kammari, B.R.; Madda, J.; Kommu, N.; Lakkadi, A.; Vuppala, S.; Tigulla, P. Synthesis of new chromeno-carbamodithioate derivatives and preliminary evaluation of their antioxidant activity and molecular docking studies. Bioorg. Med. Chem. Lett. 2017, 27, 1256-1260. [CrossRef] [PubMed]

9. Niu, H.; Wang, W.; Li, J.; Lei, Y.; Zhao, Y.; Yang, W.; Zhao, C.; Lin, B.; Song, S.; Wang, S. A novel structural class of coumarin-chalcone fibrates as PPAR $\alpha / \gamma$ agonists with potent antioxidant activities: Design, synthesis, biological evaluation and molecular docking studies. Eur. J. Med. Chem. 2017, 138, 212-220. [CrossRef] [PubMed]

10. Urbaniak, A.; Kujawski, J.; Czaja, K.; Szelag, M. Antioxidant properties of several caffeic acid derivatives: A theoretical study. C. R. Chim. 2017, 20, 1072-1082. [CrossRef]

11. Akbas, E.; Ekin, S.; Ergan, E.; Karakus, Y. Synthesis, DFT calculations, spectroscopy and in vitro antioxidant activity studies on 4-hydroxyphenyl substituted thiopyrimidine derivatives. J. Mol. Struct. 2018, 1174, 177-183. [CrossRef]

12. Gür, M.; Muğlu, H.; Çavuş, M.S.; Güder, A.; Sayıner, H.S.; Kandemirli, F. Synthesis, characterization, quantum chemical calculations and evaluation of antioxidant properties of 1,3,4-thiadiazole derivatives including 2- and 3-methoxy cinnamic acids. J. Mol. Struct. 2017, 1134, 40-50. [CrossRef]

13. Teles Fujishima, M.A.; Silva, N.S.R.; Ramos, R.S.; Batista Ferreira, E.F.; Santos, K.L.B.; Silva, C.H.T.P.; Silva, J.O.; Campos Rosa, J.M.; Santos, C.B.R. An Antioxidant potential, quantum-chemical and molecular docking study of the major chemical constituents present in the leaves of curatella americana linn. Pharmaceuticals 2018, 11, 72. [CrossRef] [PubMed]

14. Costa, J.S.; Costa, K.S.L.; Cruz, J.V.; Ramos, R.S.; Silva, L.B.; Brasil, D.S.B.; Silva, C.H.T.P.; Santos, C.B.R.; Macêdo, W.J.C. Virtual screening and statistical analysis in the design of new caffeine analogues molecules with potential epithelial anticancer activity. Curr. Pharm. Des. 2018, 24, 576-594. [CrossRef] [PubMed]

15. Hevener, K.E.; Zhao, W.; Ball, D.M.; Babaoglu, K.; Qi, J.; White, S.W.; Lee, R.E. Validation of molecular docking programs for virtual screening against dihydropteroate synthase. J. Chem. Inf. Model. 2009, 49, 444-460. [CrossRef] [PubMed]

16. Gowthaman, U.; Jayakanthan, M.; Sundar, D. Molecular docking studies of dithionitrobenzoic acid and its related compounds to protein disulfide isomerase: Computational screening of inhibitors to HIV-1 entry. BMC Bioinform. 2008, 9, 1-10. [CrossRef] [PubMed]

17. Williams, P.A.; Cosme, J.; Ward, A.; Angove, H.C.; Vinkovic', D.M.; Jhoti, H. Crystal structure of human cytochrome P450 2C9 with bound warfarin. Nature 2003, 424, 464-468. [CrossRef] [PubMed]

18. Blair-Johnson, M.; Fiedler, T.; Fenna, R. Human myeloperoxidase: Structure of a cyanide complex and its interaction with bromide and thiocyanate substrates at 1.9 A resolution. Biochemistry 2001, 40, 13990-13997. [CrossRef] [PubMed]

19. Lountos, G.T.; Jiang, R.; Wellborn, W.B.; Thaler, T.L.; Bommarius, A.S.; Orville, A.M. The crystal structure of $\mathrm{NAD}(\mathrm{P}) \mathrm{H}$ oxidase from lactobacillus sanfranciscensis: Insights into the conversion of $\mathrm{O}_{2}$ into two water molecules by the flavoenzyme. Biochemistry 2006, 2006 45, 9648-9659. [CrossRef]

20. Mohan, C.; Long, K.D.; Mutneja, M. An Introduction to Inhibitors and Their Biological Applications, 1st ed.; EMD Millipore: Darmstadt, Germany, 2013; pp. 1-48.

21. Vieira, J.B.; Braga, F.S.; Lobato, C.C.; Santos, C.F.; Costa, J.S.; Bittencourt, J.A.; Brasil, D.S.; Silva, J.O.; Hage-Melim, L.I.; Macêdo, W.J.; et al. A QSAR, pharmacokinetic and toxicological study of new artemisinin compounds with anticancer activity. Molecules 2014, 19, 10670-10697. [CrossRef] [PubMed] 
22. Santos, C.B.R.; Vieira, J.B.; Lobato, C.C.; Hage-Melim, L.I.S.; Souto, R.N.P.; Lima, C.S.; Costa, E.V.M.; Brasil, D.S.B.; Macêdo, W.J.C.; Carvalho, J.C.T. A SAR and QSAR study of new artemisinin compounds with antimalarial activity. Molecules 2014, 19, 367-399. [CrossRef] [PubMed]

23. Yalkowsky, S.H.; Valvani, S.C. Solubilities and partitioning. 2. Relationships between aqueous solubilities, partition coefficients, and molecular surface areas of rigid aromatic hydrocarbons. J. Chem. Eng. Data 1979, 24, 127-129. [CrossRef]

24. Panayiotou, C. Redefining solubility parameters: Bulk and surface properties from unified molecular descriptors. J. Chem. Thermodyn. 2017, 111, 207-220. [CrossRef]

25. Gubskaya, A.V.; Kusalik, P.G. The total molecular dipole moment for liquid water. J. Chem. Phys. 2002, 117, 5290-5302. [CrossRef]

26. Farasat, M.; Shojaei, S.H.R.; Golzan, M.M.; Farhadi, K. Theoretical study of the potential energy surface and electric dipole moment of aniline. J. Mol. Struct. 2016, 1108, 341-346. [CrossRef]

27. Tognetti, V.; Morell, C.; Joubert, L. Atomic electronegativities in molecules. Chem. Phys. Lett. 2015, 635, 111-115. [CrossRef]

28. Cunha, E.L.; Santos, C.F.; Braga, F.S.; Costa, J.S.; Silva, R.C.; Favacho, H.A.S.; Hage-Melim, L.I.S.; Carvalho, J.C.T.; Silva, C.H.T.P.; Santos, C.B.R. Computational investigation of antifungal compounds using molecular modeling and prediction of ADME/Tox properties. J. Comput. Theor. Nanosci. 2015, 12, 3682-3691. [CrossRef]

29. Yang, W.; Lee, C.; Ghosh, S.K. Molecular softness as the average of atomic softnesses: Companion principle to the geometric mean principle for electronegativity equalization. J. Phys. Chem. 1985, 89, 5412-5414. [CrossRef]

30. Nalewajski, R.F.; Korchowiec, J.; Zhou, Z. Molecular hardness and softness parameters and their use in chemistry. Int. J. Quantum Chem. 1988, 34, 349-366. [CrossRef]

31. Liu, P.H.; Hunt, K.L.C. Molecular softness, hypersoftness, infrared absorption, and vibrational Raman scattering: New relations derived from nonlocal polarizability densities. J. Chem. Phys. 1995, 103, 10597-10604. [CrossRef]

32. Ghanty, T.K.; Ghosh, S.K. Molecular Hardness, polarizability and valency variation of formamide and thioformamide on internal rotation: A density functional study. J. Phys. Chem. A 2000, 104, 2975-2979. [CrossRef]

33. Kaya, S.; Kaya, C. A new method for calculation of molecular hardness: A theoretical study. Comput. Theor. Chem. 2015, 1060, 66-70. [CrossRef]

34. Tarazona, M.P.; Sáiz, E. Understanding chemical potential. J. Chem. Educ. 1995, 72, 882-883. [CrossRef]

35. Cook, G.; Dickerson, R.H. Understanding the chemical potential. Am. J. Phys. 1995, 63, 737-742. [CrossRef]

36. Job, G.; Herrmann, F. Chemical potential-A quantity in search of recognition. Eur. J. Phys. 2006, 27, 353-371. [CrossRef]

37. Grant, G.H.; Richards, W.G. Computational Chemistry; Oxford Science Publications: Oxford, UK, 1996; pp. 1-96.

38. Anh, N.T. Regio- and stereo-selectivities in some nucleophilic reactions. In Organic Chemistry Syntheses and Reactivity; Springer: Berlin/Heidelberg, Germany, 1980; Volume 88, pp. 145-162.

39. Bassindale, A.R.; Glynn, S.J.; Taylor, P.G. Reaction mechanisms of nucleophilic attack at silicon. In The Chemistry of Organic Silicon Compounds; Patai, S., Rappoport, Z., Eds.; Wiley Online Library: New York, NY, USA, 1898; Volume 2, pp. 495-511.

40. Mihçiokur, O.; Özpozan, T. Molecular structure, vibrational spectroscopic analysis (IR \& Raman), HOMO-LUMO and NBO analysis of anti-cancer drug sunitinib using DFT method. J. Mol. Struct. 2017, 1149, 27-41. [CrossRef]

41. Zhang, G.; Musgrave, C.B. Comparison of DFT methods for molecular orbital eigenvalue calculations. J. Phys. Chem. A 2007, 111, 1554-1561. [CrossRef] [PubMed]

42. PDB—Protein Data Bank. Available online: http://www.ncbi.nlm.nih.gov/protein/ (accessed on 20 January 2018).

43. Morris, G.M.; Goodsell, D.S.; Halliday, R.S.; Huey, R.; Hart, W.E.; Belew, R.K.; Olson, A.J. Automated docking using a lamarckian genetic algorithm and empirical binding free energy function. J. Comput. Chem. 1998, 19, 1639-1662. [CrossRef] 
44. Cruz, J.V.; Serafim, R.B.; da Silva, G.M.; Giuliatti, S.; Rosa, J.M.C.; Neto, M.F.A.; Leite, F.H.A.; Taft, C.A.; da Silva, C.H.T.P.; Santos, C.B.R. Computational design of new protein kinase 2 inhibitors for the treatment of inflammatory diseases using QSAR, pharmacophore-structure-based virtual screening, and molecular dynamics. J. Mol. Model. 2018, 24, 225. [CrossRef] [PubMed]

45. Silva, R.C.; Poiani, J.G.C.; Ramos, R.S.; Costa, J.S.; Silva, C.H.T.P.; Brasil, D.S.B.; Santos, C.B.R. Ligandand structure- based virtual screening from 16-(N,N-diisobutylaminomethyl)-6 $\alpha$-hydroxyivouacapan$7 \beta, 17 \beta$-lactone compound with potential anti-prostate cancer activity. J. Serb. Chem. Soc. 2018, 83, 6472. [CrossRef]

46. Santos, C.B.R.; Ramos, R.S.; Sánchez Ortiz, B.L.; Silva, G.M.; Giuliatti, S.; Balderas-Lopez, J.L.; Navarrete, A.; Carvalho, J.C.T. Oil from the fruits of Pterodon emarginatus Vog.: A traditional anti-inflammatory. Study combining in vivo and in silico. J. Ethnopharmacol. 2018, 222, 107-120. [CrossRef] [PubMed]

47. Cruz, J.V.; Neto, M.F.A.; Silva, L.B.; da Ramos, R.; da Costa, J.; Brasil, D.S.B.; Lobato, C.C.; da Costa, G.V.; Bittencourt, J.A.H.M.; da Silva, C.H.T.P.; et al. Identification of novel protein kinase receptor type 2 inhibitors using pharmacophore and structure-based virtual screening. Molecules 2018, 23, 453. [CrossRef] [PubMed]

48. Viloria, J.S.; Allega, M.F.; Lambrughi, M.; Papaleo, E. An optimal distance cutoff for contact-based Protein Structure Networks using side-chain centers of mass. Sci. Rep. 2017, 7, 1-11. [CrossRef]

49. Pereira, A.L.; Santos, G.B.; Franco, M.S.; Federico, L.B.; Silva, C.H.; Santos, C.B. Molecular modeling and statistical analysis in the design of derivatives of human dipeptidyl peptidase IV. J. Biomol. Struct. Dyn. 2018, 36, 318-334. [CrossRef] [PubMed]

50. Padilha, E.C.; Serafim, R.B.; Sarmiento, D.Y.R.; Santos, C.F.; Santos, C.B.; Silva, C.H. New PPAR $\alpha / \gamma / \delta$ optimal activator rationally designed by computational methods. J. Braz. Chem. Soc. 2016, 27, 1636-1647. [CrossRef]

51. Rogozin, E.A.; Lee, K.W.; Kang, N.J.; Yu, H.; Nomura, M.; Miyamoto, K.I.; Conney, A.H.; Bode, A.M.; Dong, Z. Inhibitory effects of caffeine analogues on neoplastic transformation: Structure-activity relationship. Carcinogenesis 2008, 29, 1228-1234. [CrossRef] [PubMed]

52. Roy, J.; Galano, J.; Durand, T.; Guennec, J.; Lee, J.C.Y. Physiological role of reactive oxygen species as promoters of natural defenses. FASEB J. 2017, 31, 3729-3745. [CrossRef] [PubMed]

53. Działo, M.; Mierziak, J.; Korzun, U.; Preisner, M.; Szopa, J.; Kulma, A. The potential of plant phenolics in prevention and therapy of skin disorders. Int. J. Mol. Sci. 2016, 17, 160. [CrossRef] [PubMed]

54. Reinisalo, M.; Kårlund, A.; Koskela, A.; Kaarniranta, K.; Karjalainen, R.O. Polyphenol stilbenes: Molecular mechanisms of defence against oxidative stress and aging-related diseases. Oxid. Med. Cell. Longev. 2015. [CrossRef] [PubMed]

55. Gunes, A.; Coskun, U.; Boruban, C.; Gunel, N.; Babaoglu, M.O.; Sencan, O.; Bozkurt, A.; Rane, A.; Hassan, M.; Zengil, H.; et al. Inhibitory effect of 5-fluorouracil on cytochrome P450 2C9 activity in cancer patients. Basic Clin. Pharmacol. Toxicol. 2006, 98, 197-200. [CrossRef] [PubMed]

56. Drugbank. Available online: https:/ / www.drugbank.ca/unearth/ (accessed on 7 July 2018).

57. Saul, D.; Gleitz, S.; Nguyen, H.H.; Kosinsky, R.L.; Sehmisch, S.; Hoffmann, D.B.; Wassmann, M.; Menger, B.; Komrakova, M. Effect of the lipoxygenase-inhibitors baicalein and zileuton on the vertebra in ovariectomized rats. Bone 2017, 101, 134-144. [CrossRef] [PubMed]

58. Carter, G.W.; Young, P.R.; Albert, D.H.; Bouska, J.; Dyer, R.; Bell, R.L.; Summers, J.B.; Brooks, D.W. 5-Lipoxygenase inhibitory activity of zileuton. J. Pharmacol. Exp. Ther. 1991, 256, 929-937. [PubMed]

59. Allegra, M.; Furtmüller, P.G.; Regelsberger, G.; Turco-Liveri, M.L.; Tesoriere, L.; Perretti, M.; Livrea, M.A.; Obinger, C. Mechanism of reaction of melatonin with human myeloperoxidase. Biochem. Biophys. Res. Commun. 2001, 282, 380-386. [CrossRef] [PubMed]

60. Galijasevic, S.; Abdulhamid, I.; Abu-Soud, H.M. Melatonin is a potent inhibitor for myeloperoxidase. Biochemistry 2008, 47, 2668-2677. [CrossRef] [PubMed]

61. Liu, S.L.; Li, Y.H.; Shi, G.Y.; Tang, S.H.; Jiang, S.J.; Huang, C.W.; Liu, P.Y.; Hong, J.S.; Wu, H.L. Dextromethorphan reduces oxidative stress and inhibits atherosclerosis and neointima formation in mice. Cardiovasc. Res. 2009, 82, 161-169. [CrossRef] [PubMed]

62. Wu, T.C.; Chao, C.Y.; Lin, S.J.; Chen, J.W. Low-dose dextromethorphan, a NADPH oxidase inhibitor, reduces blood pressure and enhances vascular protection in experimental hypertension. PLoS ONE 2012, 9, 1-12. [CrossRef] [PubMed] 
63. Malik, U.Z.; Hundley, N.J.; Romero, G.; Radi, R.; Freeman, B.A.; Tarpey, M.M.; Kelley, E.E. Febuxostat inhibition of endothelial-bound XO: Implications for targeting vascular ROS production. Free Radic. Biol. Med. 2011, 51, 179-184. [CrossRef] [PubMed]

64. Costa, J.S.; Santos, C.B.R.; Costa, K.S.L.; Ramos, R.S.; Silva, C.H.T.P.; Macêdo, W.J.C. Validation of computational methods applied in molecular modeling of caffeine with epithelial anticancer activity: Theoretical study of geometric, thermochemical and spectrometric data. Quím. Nova 2018, 7, 732-742. [CrossRef]

65. STATISTICA (Data Analysis Software System), Version 6.1; StatSoft Inc.: Tulsa, OK, USA, 2004.

Sample Availability: Samples of the compounds are not available from the authors.

(C) 2018 by the authors. Licensee MDPI, Basel, Switzerland. This article is an open access article distributed under the terms and conditions of the Creative Commons Attribution (CC BY) license (http:// creativecommons.org/licenses/by/4.0/). 